\title{
Learning conditions for continuous improvement in a public service organization
}

Agneta Halvarsson Lundkvist and Maria Gustavsson

The self-archived postprint version of this journal article is available at Linköping University Institutional Repository (DiVA):

http:/ / urn.kb.se/ resolve?urn=urn:nbn:se:liu:diva- 152661

N.B.: When citing this work, cite the original publication.

Halvarsson Lundkvist, A., Gustavsson, M., (2018), Learning conditions for continuous improvement in a public service organization, J ournal of Workplace Learning. https:// doi.org/ 10.1108/J WL-03-20180049

Original publication available at:

https:/ / doi.org/ 10.1108/JWL-03-2018-0049

Copyright: Emerald

http:// www.emeraldinsight.com/ 


\section{Learning Conditions for Continuous Improvement in a Public Service Organization}

Purpose: This study focuses on a transformation effort in a social welfare department of a Swedish municipality where continuous improvement, which is a Lean principle, was introduced in employees' everyday work via a workplace development programme (WPDP). The aim of this paper is to explore the conditions (internal and external) that enabled or constrained employee learning during the introduction of continuous improvement into employees' everyday work in a WPDP-supported social welfare department.

Design/methodology: This case study is based mainly on 22 semi-structured interviews with individuals holding different positions in the department and overarching municipality.

Findings: The findings show that multiple and emerging conditions, both internal and external, shaped a predominantly restrictive learning environment during the introduction of continuous improvement into the social welfare department. The major conditions identified were related to 1) the initial implementation and top management's steering and monitoring of the 'Lean investment', 2) activities and support provided by the WPDP, 3) activities and support provided by the internal Lean support team, and 4) first-line managers' abilities to facilitate employee learning.

Originality/value: Apart from unique empirical material depicting an effort towards change under conditions far from favourable for employee learning, the value of this study lies in the attention given to the external dynamics that drive change in line with the concept of new public management in public service organizations, including a WPDP that supported the social welfare department.

\section{Introduction}

New public management (NPM) has become a commonly used improvement approach in the public sector, encouraging administrations to transform into more efficient and more business-like organizations (Hood, 1996). In this article, the focus is on such a transformation effort in a social welfare department in a Swedish municipality, where continuous improvement was introduced in employees' everyday work. Continuous improvement has been considered a suitable method for making production and work processes more efficient and for reducing waste (Womack, 1991). This method originates from the philosophy of Lean 
production (Lean), which in accordance with NPM, aims to increase efficiency and control with regard to the processes mentioned. A change effort, such as introducing the Lean principle of continuous improvement into a public service organization, can, however, be challenging.

One such challenge results from increasing institutional complexity accompanied by conflicting demands (Greenwood et al., 2011), often due to reforms stemming from politicians' and high-ranking officials' 'modern', 'symbolic promises' rather than wellconceived plans for 'real' change (Christensen and Lægried, 2011). A Norwegian study of central public organizations noted that most symbolic reform policies are not coupled as tightly as they should be to the practical aspects of implementing change (Christensen and Lægried, 2015). This indicates that organizations planning to introduce continuous improvement may struggle to find practical solutions when acting according to the policies, and prevailing internal organizational conditions may contribute to this type of decoupling (Forssell, 2001). Therefore, as several workplace learning studies note, a major challenge when introducing a new way of working to employees is to provide an enabling or rich learning environment in which employees' learning is supported (Billett, 2004; Ellström, 2010, 2011; Fuller and Unwin, 2004). Various conditions may contribute to shaping the learning environment, which will be elaborated in the conceptual framework section. The importance of top management steering of change projects to achieve the intended outcome has also been noted (Brulin and Svensson, 2012). Lack of steering may contribute to change projects being run 'on the side' and eventually quietly disappearing from the organization's agenda (Brulin and Svensson, 2012).

Previous research has shown that public sector organizations must address the challenges mentioned above to achieve planned organizational change (Christensen and Lægried, 2015; Brulin and Svensson, 2012; Ellström, 2011). For this reason, organizations sometimes search for external support such as regional or national workplace development programmes (WPDP) (Alasoini, 2016), which offer varying types of support in the form of courses, training, coaching or networking to managers or employees in workplaces or entire organizations seeking to change work processes. Notably, a WPDP can be an important driving force for learning and thus for achieving planned change if the competence development activities provided by the WPDP are integrated with employees' everyday work activities (Halvarsson Lundkvist and Gustavsson, 2018). This is because the impact of WPDP competence development activities may increase if the learning conditions within the 
organization are enabling (Ellström, 2011; Evans, 2015). In this regard, interesting questions include in what ways a WPDP may support an organization during a change effort such as introducing continuous improvement into employees' everyday work and what internal organizational conditions may enable or constrain learning during the change effort. However, it is also important to consider external conditions such as political agendas and economic pressure, which are dynamics that may drive change in public service organizations (Elkjær et al., 2007; Rule et al., 2016).

The aim of this paper is to explore the conditions (internal and external) that enabled or constrained employee learning during the introduction of continuous improvement into employees' everyday work in a WPDP-supported social welfare department. The social welfare department received support, mainly in the form of competence development activities (Lean courses), from a national WPDP initiated by a foundation, owned by national unions and a large employer association in the Swedish public sector. The social welfare department was one of the first to join the WPDP, which was influenced by NPM.

The outline of this paper is as follows. The next section contains the paper's conceptual framework. An account of the methods deployed in the study follows. Then, empirical illustrations demonstrate the paper's arguments. A concluding discussion ends the paper.

\section{Conceptual Framework}

In the analysis, the focus is on the conditions in the social welfare department that enabled or constrained workplace learning while continuous improvement was introduced in employees' everyday work. As such, workplace learning is an integral social and participatory process of everyday work, and a number of conditions shape the workplace environment and its invitational qualities (Billett, 2004; Evans et al., 2006; Fuller and Unwin, 2004; Gustavsson, 2009).

Using a workplace learning perspective, informed by situated learning, the conditions for learning are analysed through the theoretical framework of expansive-restrictive learning environments (Fuller and Unwin, 2004). Studies show that expansive learning environments support dialogue and problem solving across the boundaries of different work groups. In expansive learning environments, many forms of expertise are utilized, allowing employees to change well-known work routines and move towards new ideas (Fuller and Unwin, 2011) through expansive (Engeström, 2014) or developmental learning (Ellström, 2006). Thus, expansive learning environments are innovative, and employees' development is therefore 
closely related to organizational development (Fuller and Unwin, 2011) and transformation of work (Engeström, 2014). Conversely, restrictive learning environments are associated with constraining learning conditions (Fuller and Unwin, 2004). Restrictive learning environments are characterized by less diversity, separation of the (learning) goal of individuals from the development of the organization and a top-down approach to learning, where 'experts' transmit knowledge to novices (the employees) (Fuller and Unwin, 2011). The learning environment impacts both 'learning through everyday activities and learning intended to be provided through intentional guided practices' (Billett, 2002, p. 478). In the social welfare department studied here, intentional guided practices include the WPDP and the internally organized support in the department, which will be elaborated on.

In previous research, a number of internal organizational conditions have been shown to create expansive (or restrictive) learning environments. Examples of internal contextual conditions shaping learning environments in organizations are the complexity and variety of the work tasks and the level of freedom they provide (Ellström, 2010). Opportunities for feedback and reflection for managers and employees in combination with sufficient resources, including time, for managers to support employees' learning contribute to creating expansive (enabling) learning environments (Ellström, 2006). Furthermore, studies show that a culture of openness, trust and allowing risk taking contributes to expansive learning environments (Ellström, 2010). However, opportunities for learning that arise for employees in their everyday work may remain unused by some groups or individuals (Gustavsson, 2007). Thus, the affordances in organizations regarding employee and manager participation in work activities are regulated by norms and practices in the workplace yet also dependent on the will of managers and employees to engage in everyday work or intentionally organized learning activities in the workplace (Billett, 2004).

Regardless of the support from an external change agent such as a WPDP, changes in work methods or work processes made by employees, beyond minor adjustments, usually involve support from other functions, such as first-line managers or Lean coaches (Gustavsson, 2009; Høyrup 2010). It seems that first-line managers or supervisors are indispensable in the creation of an expansive learning environment (Lancaster and Di Milia, 2015), which also indicates that the pedagogic interventions of first-line managers shape employees' learning environments (Döös et al., 2015). Opportunities for cooperation among employees are a condition that seems to enhance learning outcomes (Kyndt, 2016; Lantz, 2011), including self-organized practices (Manuti et al., 2017). Altogether, the cited studies indicate that 
managers shape the learning environment for employees and thus play an important facilitating role in workplace learning. However, the literature also points to the need to support managers in public service organizations to develop their role as facilitators of employees' learning in improvement work (Gustavsson, 2009).

The internal conditions for learning in an organization may be affected by external conditions. Elkjær and colleagues (2007) advocate that political agendas, the general economy and discourses should be considered when researching workplace learning to identify managers' and employees' opportunities for learning and development in everyday work. Similarly, Rule et al. (2016) point to the importance of taking such external dynamics and macro contexts into account to understand how to support learning during change processes in organizations. The present study focuses on one external actor in particular, namely, the aforementioned WPDP. Case studies show that competence development provided by a WPDP with the aim of improving work processes can be an important driving force for learning if the competence development activities are integrated with employees' everyday work (Halvarsson Lundkvist and Gustavsson, 2018).

\section{Research Setting}

A case study was conducted in a municipality's social welfare department (approximately 3,000 employees), which comprised over 100 work units in four operations (elderly care, care for the disabled, family support and a social benefits division). The introduction of continuous improvement into employees' everyday work was referred to as the 'Lean investment'. An internal Lean support team with Lean coaches assisted managers throughout the department in introducing continuous improvement in employees' everyday work, and the aforementioned WPDP provided Lean courses for both managers and Lean coaches. The Lean support team decided that implementing continuous improvements was mandatory; therefore, this topic was the focus of unit manager support. Thus, in practice, the 'Lean investment' meant introducing continuous improvements.

\section{Method}

The case study includes 22 individual semi-structured interviews (lasting 60-120 minutes) in the municipality. Table 1 describes the 20 initial interviews and the interviewees' roles or functions. In addition, two follow-up interviews were conducted five years after the initial interviews. 
Table 1. An overview of the interviews conducted.

\begin{tabular}{lll}
\hline Role or function & Initial interviews, 2011 (number of people) & Follow-up interviews, 2016 \\
\hline Politicians & Municipality counsellors (including mayor) (2) & \\
& Social welfare committee chairperson (1) & \\
& Former social welfare committee chairperson & \\
& $(1)$ (opposing party) & \\
Management (five levels) & Municipality director (1) \\
& Social welfare director (1) \\
& Social welfare programme directors (2) \\
& Social welfare chiefs of operations (2) & \\
Union & Unit managers, one from each operation (4) \\
Development division & Head union leader (1) \\
Lean support team & Manager of development department (1) & Lean support leader (1) \\
& Lean support leaders (2) & Lean coach (1) \\
\hline
\end{tabular}

Sixteen interviewees were selected because of their key positions in the municipality, department or Lean support team. In addition, four unit managers who had shown an interest in the 'Lean investment' were selected in conjunction with the Lean support team manager. The interview guide included questions about the organizing of the 'Lean investment' and enabling and constraining conditions during the change effort as well as questions about the immediate results of the improvement work. In addition, written plans describing the 'Lean investment' and documents such as organizational charts were collected.

A 3-hour seminar, involving 28 individuals (interviewees and other key persons), was coorganized by one of the authors, other members of the research team and the Lean supportteam manager 18 months into the 'Lean investment'. During the seminar, minutes were recorded regarding the organization of the 'Lean investment' and the managers' and employees' perceptions of the continuous improvement implementation in the work units.

The role of the researchers was external to the WPDP, the municipality and its social welfare department and did not affect the outcome of the 'Lean investment'. The original interviews were part of a comprehensive study in eight large public service organizations supported by the WPDP.

Data analysis was based on the interview transcripts and the minutes of the seminar. In the first analysis step, qualitative content analysis was used to sort the conditions into two 
categories, i.e., internal or external. In a second step, the internal and external conditions, respectively, were sorted into subcategories of enabling or constraining the 'Lean investment' by using the theoretical framework of expansive-restrictive learning environments (Fuller and Unwin, 2004). In the process of analysis, themes emerged demonstrating important conditions that had an effect on employees' learning as continuous improvement was introduced in their everyday work. The themes correspond with the four sections of the findings.

Follow-up interviews conducted five years later with the Lean support team leader and a Lean coach provided a retrospective glimpse into the events involved with the 'Lean investment' and whether the 'Lean investment' had been sustained or not, for example, by further support from the internal Lean support team or managers. The follow-up interviews provided information about the general lack of recorded effects of the 'Lean investment' across the social welfare department.

\section{Findings}

The following section focuses on external and internal conditions that enabled or constrained employee learning while continuous improvement was introduced into their everyday work. The conditions are viewed from the perspectives of top management, the Lean support team leader, internal Lean coaches and unit managers.

\section{Initial Implementation and Top Management's Steering and Monitoring of the 'Lean} Investment'

An amendment in the Swedish municipality law (Kommunallagen), chapter 6, paragraph 7, put pressure on local authorities to better control processes in public service organizations. At the same time, poor finances and internal political demands in the municipality on operations to become more client/patient responsive put pressure on the social welfare department director to make work processes in the department more efficient, which led to the 'Lean investment'.

The social welfare director ordered all managers in the department to use Lean to develop the work units (continuous improvement was mandatory, while other Lean features were not). A Lean support team was organized, which was assigned the task of supporting the managers, while continuous improvement was introduced in the work units. The idea was that the managers eventually would be able to facilitate their employees' learning well enough to 
secure continuous improvement in everyday work processes. Looking back at the events that led to a quick start of the 'Lean investment', the Lean support team manager states:

Then ... just like that [snaps fingers], we were to start, but how do we go about it? [...] With this [snaps fingers again] I suddenly realized that the investment in Lean had become my responsibility and how was I supposed to ... and then the head of the Development division and I went to Stockholm to buy courses from the WPDP [laughs]. Yet, the first plan was to give courses ourselves. (Lean support team manager)

The excerpt provides a glimpse of two emerging conditions that would later contribute to an unfavourable learning environment in the department. The first was that the quick start forced the support team manager (Lena) to buy courses from a WPDP, which she knew little about and from which she would obtain no assistance in building internal support for the managers. The second condition was that she found herself rather alone in designing the 'Lean investment', and eventually she started looking for steering or monitoring from top management, which she felt was lacking. Lena continues to contemplate:

As I recall, they gave me an enormous amount of freedom to steer this [...] Researcher: Also in the design of the Lean investment? Yes, exactly, how we were to build the whole thing, and I can still feel ... [draws a deep breath to demonstrate fear] the fear when I thought of how they just left it with us. Researcher: What are your feelings now? Well, really, that was not such a good idea [laughter] that the departments top managers though it ok for me alone to structure this. I talked to my boss only [the head of the Development department], who agreed to everything I said, and I don't think it ever reached the department's management group. [...] If you look back, how would you... Well, we should have envisaged this a lot more, although I am happy with some parts, but I would have wanted a steering group in the form of the department management group. (Lean support team manager)

The following excerpt shows that the social welfare director seemed to have been more of a symbolic figurehead than someone who monitored and steered the 'Lean investment':

Carl [the social welfare director] also has a symbolic value because he articulates Lean, which has an effect on managers [...] He says that Lean is to be implemented [...]. Yet, we managers have not been as keen to ask for results. [...] I hope that we will get better at this. (Different voices at seminar)

Thus, the 'Lean investment' exhibited features indicating that the intended policy was partially decoupled with the actual change processes (Christensen and Lægried, 2015). In addition, some 14 months into the 'Lean investment', there was a change in political majority in the municipality and department councils. The following excerpts explain what happened: 
The new majority is very set on exposing the operations to competition, which is a fundamentally different way of organizing. We are built to produce only, and now we face this transition. [...] This is rather challenging. (Social welfare director)

Then again, there is also the privatization. If all of that takes over ... it all depends on political decisions and positions. (Programme director 2)

I don't see Lean as something that can fix big structural changes. Researcher: Can you explain what you mean? I have two examples, we found ourselves in the midst of a financial crisis [...].

The other one is the change of political majority. (Municipality director)

As demonstrated, the political decision to engage the department in another major reform was not ideal because it resulted in conflicting demands and increased complexity in the already financially strained department (Greenwood et al., 2011). However, other problems also emerged.

\section{Activities and Support Provided by the WPDP}

As depicted, the hasty decision to invest in Lean forced the Lean support team manager to buy courses from a WPDP, instead of adhering to the original idea, which was to educate staff within the department so that they could provide courses to unit managers. The WPDP provided 3-day courses for 115 unit managers. The courses comprised different theoretical blocks of Lean philosophy and Lean tools. Lean coaches and top-level management received an additional 12-day course, and the Lean coaches received another 3-day course focused on change management on top of that. The following problem existed: the unit managers were ordered to take the course, and they were not able to co-design any part of it or decide whether they had the time to attend the course or had any interest in the subject matter. The courses provided by the WPDP in question varied in quality, and they were not adapted to the public service sector, as they included many features that were mostly useful in a manufacturing context:

In hindsight, I can see that it was rather set on production, and I don't think they or we understood this back then [...], it was not so set on services really. (Lean coach 2)

Some managers were disappointed and wished the courses had provided more support in terms of learning Lean methods, although they were able to utilize some parts of what they had learned about implementing continuous improvement:

Well, the course quality was alternatively good and not so good. I would have wished for a more focused course. (Chief operations 1) 
It does not impress me. I drew a blank. Most of it was manuscript reading. The guy who led it was inexperienced and insecure. (Unit manager 1)

We did many exercises, which gave a lot; and the study visit at a [local manufacturing company] was good. I can take home things from that. (Unit manager 2)

One of the Lean coaches explained that in retrospect the WPDP courses did not provide the coaches with enough training for the task set out for them, which contributed to coaches using only a few Lean tools while supporting the managers (elaborated in the next section).

The particular WPDP with which the department chose to engage did not formally demand top-level management engagement in the form of steering or monitoring of practical changes. There was only a minimal amount of integration between the competence development activities provided by the WPDP and the internal coaching activities, and the Lean support team and officials in the department did not receive assistance from the WPDP in planning and organizing the 'Lean investment':

I actually do not recall any advice or support from them [the WPDP] in thinking about the design [of the support team or implementation process]. (Lean support team manager)

\section{Activities and Support Provided by the Internal Lean Support Team}

The Lean coaches had been given significant yet difficult roles in forming a bridge between political and top management aspirations and in the practical implementation of continuous improvement in employees' everyday work, which the following excerpt shows:

The Lean coaches' roles are to coach the managers and be part of a value flow analysis. They help the managers with material and train them. (Assistant Lean support team manager)

A Lean coach explained that value flow analyses (VFAs) dominated the introduction phase [a VFA is a Lean tool used to carefully examine work processes to determine what to change]:

\footnotetext{
We made a value flow analysis, because we knew how to use that tool. No matter what the problem was, we made a value flow analysis [giggles]. It was not until much later that we understood that this was not so smart. [...] We could have done other things but we had not learned that yet. (Lean coach 2)

After the course, all managers make a value flow analysis together with a Lean coach. The Lean coach phones the unit manager after they have participated in the course and asks them when and how they want to proceed. (Lean coach 1)
}

Although the first telephone call to the unit managers came from one of the Lean coaches, the coaches had no mandate to demand that a unit manager take the lead in introducing 
continuous improvement to the employees or even participate during the coach's visits to the unit. This was reflected in the follow-up interview with one of the Lean coaches:

This was something on the side. It was an investment in Lean to be made, which, from the start, had no coupling with reality. Instead, we took a problem area [from the work unit] pulled it out and worked on it over here [draws a picture of a separate space], did something about it, and then we put it back [into the work unit] again. [...] The department's management group got a mediocre education, and the employees only learned from us [coaches] and in between there was a gigantic gap. Researcher: You mean all the unit managers? Yes, and there were quite a few of them. (Lean coach 2)

Even so, the coaches found that some positive things came out of the first VFA session, where the introduction of continuous improvement was made, especially if the unit manager was sufficiently engaged. Improvement projects started, and some improvement in work processes was seen in work units, such as nurses' aides being able to spend more time with patients and improved routines for laundering, etc.

\section{First-Line Managers’'Ability to Facilitate Learning for Employees}

As mentioned, the 'Lean investment' was set up such that unit managers were to introduce the concept of continuous improvement to their unit's employees and facilitate learning for the employees so that they could continuously improve their work processes. Activities provided by the WPDP and coaches from the department's internal Lean support team were to educate and support the managers in doing so. However, this did not work out as planned, despite the social welfare director's direct order to 'implement Lean'. A Lean coach who supported 15 unit managers looks back:

Researcher: You say that some unit managers were not present at the VFA, how often did that happen? More often than not. [...] well, we had no mandate to demand that they be present. (Lean coach 2)

Nevertheless, there were learning opportunities for managers, but they remained unused by many of the unit managers (Gustavsson, 2007) due to lack of time, managers' personal preferences and possibly lack of necessary leadership skills, as indicated in the following excerpts:

I know that I belong to those [unit managers] who are the most positive. Far from everyone is positive, and that is their problem. (Unit manager 3)

I'm thinking about the leadership and how the old model of being a manager must change for this to continue. (Lean coach 1) 
However, as seen in the following excerpts, the major reason managers did not engage seemed to be time shortage:

The problem for me is to take this [the VFA] and apply it to other situations. The problem is also that we have a stressful work situation. (Unit manager 3)

We have been given considerably more to do in reporting upwards, so to speak. (Unit manager 4)

We need to make sure that there is time to work with this [...] that we are not forced to slim down so much that there is no time. (Programme director 1)

The managers had to balance the immediate demands of their work, such as administrative duties, which included 'reporting upwards' on other matters, with the 'Lean investment', and relatively little attention could be given to supporting their employees' learning and organizing of work towards continuous improvement in everyday work. Eventually, the 'Lean investment' dissipated after the department split into a production and a procurement division, as expressed by the Lean support team manager five years after its initiation:

Well the two gentlemen [directors of each division] at the top of each division could not agree on where to place the support division [...], so when one of them said 'you need to ask him', the other one replied, 'no you need to ask him' [laughs]. So I decided to dismantle the Lean support team, and nobody has asked me why or questioned the dismantling.

In summary, there were both external and internal conditions that worked to enable or constrain employee learning during the introduction of continuous improvement into employees' everyday work; these conditions are summarized in Table 2. 
Table 2. External and internal conditions that shaped the learning environment.

EXTERNAL CONDITIONS

\section{INTERNAL CONDITIONS}

\section{Shaping an expansive learning environment}

External (political) pressure on the municipality - the introduction of a new law concerning the control of processes in public service organizations

Poor finances and political demands in the municipality - added pressure to make the 'Lean investment'

Buying tailored courses provided by the external WPDP (to some extent)
(Symbolic) leadership of the social welfare director and his order to 'implement Lean'

In the beginning, the organization of an internal Lean support team in the department to support the first-line managers to become facilitators of employee learning

\section{Shaping a restrictive learning environment}

New political demands leading to a split of the department into two divisions

Not enough support provided by the WPDP for the 'Lean investment' to progress in the department
Conflicting demands at the top management level; a lack of monitoring and steering the 'Lean investment' from top management

Decoupling of a political vision and the practical change effort

Gradually, a dismantling of the Lean support team

Limited resources for first-line managers to facilitate employee learning during the introduction of continuous improvement

In the following section, the abovementioned conditions are discussed.

\section{Discussion}

The findings provide an example of how the interplay among various external conditions, including the WPDP, affected the internal organizational conditions in the social welfare department. Unfortunately, most of the conditions worked to restrict the learning environment (Fuller and Unwin, 2004; 2011), and the 'Lean investment' as a whole seems to have failed because it gradually dissipated.

The external WPDP was, in theory, intentionally designed (Billett, 2002) to support the social welfare department to enable the successful establishment of a supportive learning environment for managers in the department, so that they, in turn, could facilitate employee 
learning regarding how to engage in continuous improvement in everyday work. In theory, the WPDP would be an external 'condition' that, in a broad sense, would have provided individuals at different levels of the social welfare department with a knowledge of how to create an enabling learning environment throughout the department.

Furthermore, external conditions, such as a general financial crisis, political decisions in the social welfare and municipality councils, and the external WPDP, had a vital influence on the internal organizational conditions during the 'Lean investment'. The financial crisis and the overarching decision in the municipality to become more client/patient responsive seem to be factors in generating internal conditions that expanded the learning environment by triggering the 'Lean investment' process and the accompanying competence development activities. However, the general financial crises also lessened managers' resources for facilitating employee learning in everyday work (Ellström, 2010); additionally, the political decision to privatize some of the operations, which led to the department split into two divisions, made the top and unit managers' work more complex (Greenwood et al., 2011). This decision may have contributed to top management's inability to monitor and make adjustments to the 'Lean investment'. Nevertheless, some external conditions factored in as negative pressure on the internal organizational conditions because they decoupled the political vision from the practical change effort in different ways (Christensen and Lægried, 2015) and consequently shaped the learning environment in a restrictive way.

The separation between the production of public services and the procurement not only led to the dismantling of the internal Lean support but also resulted in the absence of individuals available to motivate unit managers to keep up the 'Lean investment'. In addition, no one examined the effects of the 'Lean investment'. Thus, the 'Lean investment' was not sustained throughout the department in a formalised way. Regardless, some positive effects from the 'Lean investment' may have remained after five years, and employees in some work units may have maintained continuous improvement in their everyday work; however, if they did, it was all up to the individual unit manager and the employees. This finding indicates that few managers showed an interest in introducing continuous improvement into their work units even when they were ordered to do so. This lack of manager interest was unfortunate because a successful 'Lean investment' depends on managers' willingness to take on a key role as the facilitator of employee learning regarding how to continuously improve everyday work (Gustavsson, 2009). Personal reasons may account for the lack of manager motivation; additionally, the internal organizational conditions may have diminished the managers' 
engagement along with the motivation to drive the 'Lean investment' in work units (Eraut, 2004).

The plan was well intentioned and set out to educate and internally support unit managers with regard to this facilitating role; nonetheless, it was difficult to put this notion into practice because of the abovementioned conditions. Therefore, many unit managers lacked the necessary time and/or interest involved in facilitating learning for their employees. Providing the managers with a key role in transforming work, without giving them the necessary resources to support employee learning, may in fact have had a devastating effect on the change effort, as previous studies have shown (Ellström, 2011). Prior literature has demonstrated that a lack of manager support may endanger change efforts in organizations (Döös et al., 2015: Gustavsson, 2009). Consequently, because the unit managers were indispensable to the change process (Lancaster and Di Milia, 2015), the learning conditions in most work units would not have been sufficient to increase employee understanding of how to carry out continuous improvement in everyday work. Therefore, there were missed opportunities for cooperation among employees, through additional VFAs or change projects deriving from them (Kyndt, 2016), and it would seem that in the majority of work units, only those employees who were able to self-organize communities became engaged in continuous improvement. This finding implies that minor efforts to use continuous improvement may have yielded positive organizational outcomes locally (Manuti et al., 2017). Notably, in this regard, different levels and units in the social welfare department may have experienced different learning conditions and would have had diverse pre-existing learning environments and deeply different work processes, which have not been investigated.

The question arises as to whether the WPDP could have done anything to mitigate the constraining conditions that shaped a restrictive learning environment in the social welfare department. As previously mentioned, the external WPDP did not make cognizant decisions about matters that, according to the literature (Brulin and Svensson, 2011; Ellström, 2010; Evans, 2015; Halvarsson Lundkvist and Gustavsson, 2018), are important to achieving organizational development through employee learning. The WPDP did not demand that the top management monitor and steer the 'Lean investment' and gave no advice on how to organize the 'Lean investment' or internal support for unit managers. Furthermore, the WPDP Lean courses had not been adjusted to suit public service organizations, and many examples were taken from the manufacturing industry. This notion is not surprising because the Lean concept was new to the public service sector at the time. However, because the 
WPDP did very little to integrate learning of continuous improvement with the work of the managers and Lean coaches and because the managers and Lean coaches were not invited to co-design such learning activities, opportunities to adjust the courses to better suit public service organizations were lost. These WPDP shortcomings affected the internal conditions in the social welfare department. Nevertheless, the findings suggest that better WPDP support may have led to a tighter coupling between high-level official policies and the practical transformation attempt, which may have improved some of the organizational conditions that shaped the learning environment in the social welfare department.

\section{Conclusions}

As previously mentioned, unit managers were the key players in shaping the learning environment for employees, but individuals with other roles in the department, such as the Lean support team and top managers, as well as politicians, were players in shaping the internal organizational conditions that, in turn, shaped the learning environment for unit managers. From the unit managers' perspective, many of the conditions presented here constrained their learning regarding how to introduce and implement continuous improvement into employees' everyday work. The same conditions shaped the employees' learning environments because unit managers were tasked with facilitating employee learning and ultimately their continuous improvement work. From the Lean support team's view, the presented conditions affected their ability to provide support that would enable managers to develop a facilitating role in the 'Lean investment'. From the top management's view, some conditions may have contributed to their decoupling from the practical change effort and certainly to increasing the complexity and contradictoriness of their work. Finally, from the politicians' view, the conditions they created made the social welfare department far from business-like because money was wasted to invest in a Lean venture that was not sustained. Thus, the paradoxical conclusion can be made that the concept of NPM motivated officials of the social welfare department and politicians to take after the private sector and become more business-like by implementing Lean (starting with continuous improvement); some months later, the NPM logic guided new politicians towards splitting the department into two divisions. The latter decision had a devastating effect on the first decision because it made the 'Lean investment' impossible to sustain.

Another conclusion is that, whether adhering to the ideas of NPM or not, a WPDP that does not consider all the mentioned perspectives is less likely to succeed in providing 
comprehensive support to public service organizations. Decisions regarding how to handle pressure that external conditions place on organizations are typically not made by the individuals who put the change effort into practice. This finding was certainly the case in the studied social welfare department. Therefore, a successful change effort seems not to automatically follow from simply joining a WPDP. Officials of a WPDP need to promote a well-functioning internal support structure in the organization they support. Ideally, activities from both supporter and supported organizations are integrated to create an expansive learning environment in which employee learning is enabled in everyday work. Furthermore, employee learning and organizational development need to be closely monitored by top management and supported by municipality politicians who refrain from placing conflicting demands on the practice they aim to change.

\section{References}

Alasoini, T. (2016), Workplace Development Programmes as Institutional Entrepreneurs Why they Produce Change and Why they do not. Aalto University, Department of Industrial Engineering and Management.

Billett, S. (2002), “Workplace pedagogic practices - Co-participation and learning”, Journal of Workplace Learning, Vol. 50 No 4, pp. 457-481.

Billett, S. (2004), "Workplace participatory practices - Conceptualising workplaces as learning environments". Journal of Workplace Learning, Vol. 16 No 6 pp. 312-324

Brulin, G., and Svensson, L. (2012), Managing Sustainable Development Programmes - A Learning Approach to Change. Gower, Farnham, UK.

Christensen, T. and Lægreid, P. (2011), “Complexity and hybrid public administration Theoretical and empirical challenges”. Public Organization Review, Vol. 11 No 4, pp. 407-423.

Christensen, T. and Lægreid, P. (2015), “Administrative reform policy - The challenges of turning symbols into practice", Public Organization Review: a Global Journal, Vol. 3, pp. 3-27.

Döös, M. Johansson, P. and Wilhelmson, L. (2015), "Beyond being present - learningoriented leadership in the daily work of middle managers", Journal of Workplace Learning, Vol. 27 No. 6, pp.408-425.

Elkjaer, B., Høyrup, S. and Pedersen, K. (2007), “Contemporary Nordic Research on Workplace Learning”, Chisholm L., Fennes H. and Spannring, R. (Eds.) Competence 
Development as Workplace Learning. Innsbruck University Press, Innsbruck, Germany, pp. 19-42.

Ellström, P.-E. (2006), “Two logics of learning”, E. Antonacopoulou, P. Jarvis, V. Andersen, Elkjaer, B. and Høyrup, S. (Eds.), Learning, Working and Living - Mapping the Terrain of Working Life Learning. Hampshire, Palgrave Macmillan, pp.33-46.

Ellström, P.-E. (2010), “Organizational learning”. Peterson, I.P., Baker, E. and McGaw, B. (Eds.), International Encyclopaedia of Education, Elsevier, pp. 47-52.

Ellström, P.-E. (2011), "Informal learning at work: conditions, processes and logics". Malloch, M., Cairns, L., Evans, K. and O'Connor, B. N., (Eds.). The SAGE Handbook of Workplace Learning, pp 105-119.

Engeström, Y. (2014), Learning by Expanding. Cambridge, Cambridge University Press. Eraut, M. (2004), "Informal learning in the workplace", Studies in Continuing Education, Vol. 26 No 2, pp. 247-273.

Evans, K. (2015), "Developing knowledgeable practices at work”, Elg, M., Ellström, P.-E., Klofsten, M. and Tillmar, M. (Eds.). Sustainable Development in Organizations Studies on Innovative Practices, Cheltenham, Edward Elgar, pp. 109-126.

Evans, K., Hodkinson, P., Rainbird, H. and Unwin, L. (2006), Improving Workplace Learning, London/New York, Routledge Taylor and Francis Group.

Forssell, A. (2001), "Reform theory meets new public management", Christensen, T. and Lægreid, P. (Eds.), New Public Management - The Transformation of Ideas and Practice, Aldershot, UK, Ashgate, pp. 261-287.

Fuller, A. and Unwin, L. (2004), "Expansive learning environments - Integrating organizational and personal development”, Rainbird, H., Fuller, A. and Munro, A. (Eds.), Workplace Learning in Context, London/New York, Routledge Taylor and Francis Group, pp. 46-49.

Fuller, A. and Unwin, L. (2011), "Workplace learning and the organization”. Malloch, M. Cairns, L., Evans, K. and O'Connor, B.N. (Eds.), The SAGE Handbook of Workplace Learning, Sage Publications, pp. 46-59.

Greenwood, R., Raynard, M., Kodeih, F., Micelotta, E. R. and Lounsbury, M. (2011), "Institutional complexity and organizational responses", Academy of Management annals, Vol. 5 No. 1, pp. 317-371.

Gustavsson, M. (2007), “The potential for learning in industrial work”, Journal of Workplace Learning, Vol. 19 No 7, pp. 453-463. 
Gustavsson, M. (2009), "Facilitating expansive learning in a public sector organization", Studies in Continuing Education, Vol. 31 No. 3, pp. 245-259.

Halvarsson Lundkvist, A. and Gustavsson, M. (2018), “Conditions for Employee Learning and Innovation - Interweaving Competence Development Activities Provided by a Workplace Development Programme with Everyday Work Activities in SMEs", Vocations and Learning, Vol. 11, No. 1, pp. 45-63.

Hood, C. (1996), "Exploring variation in public management reform of the 1980's for all seasons", Public Administration, Vol. 69, pp. 3-19.

Høyrup, S. (2010), “Employee-driven innovation and workplace learning - Basic concepts, approaches and themes, Transfer, Vol. 16 No. 2, pp. 143-154.

Kyndt, E., Vermeire, E. and Cabus, S. (2016), "Informal workplace learning among nurses Organisational learning conditions and personal characteristics that predict learning outcomes", Journal of Workplace Learning, Vol. 28 No. 7, pp.435-450.

Lancaster, S. and Di Milia, L. (2015), "Developing a supportive learning environment in a newly formed organisation", Journal of Workplace Learning, Vol. 27 No. 6, pp.442456.

Lantz. A. (2011), "Teamwork on the line can pay off down the line", Journal of Workplace Learning, Vol. 23 No. 2, pp. 75-96.

Manuti, A., Impedovo, M. A. and De Palma, P. D. (2017) "Managing social and human capital in organizations: Communities of practices as strategic tools for individual and organizational development", Journal of Workplace Learning, Vol. 29 No 3, pp.217234.

Rule, J., Dunston, R. and Solomon, N. (2016) "Learning and change in the redesign of a primary health care initiative", Journal of Workplace Learning, Vol. 28 Issue: 7, pp. 451-467,

Womack, J., Jones, D. and Roos, D. (1991), The Machine that Changed the World - The Story of Lean Production, New York, Harper Perennial. 